Association for Information Systems

AIS Electronic Library (AISeL)

Wirtschaftsinformatik 2021 Proceedings

Track 7: Digital Services and Smart Product-

Service Systems

\title{
Becoming a Product-Service System Provider - A Maturity Model for Manufacturers
}

Björn Häckel

FIM Research Center, Hochschule Augsburg

Rocco Huber

Fraunhofer FIT

Bastian Stahl

FIM Research Center, Hochschule Augsburg

Maximilian Stöter

Fraunhofer FIT

Follow this and additional works at: https://aisel.aisnet.org/wi2021

Häckel, Björn; Huber, Rocco; Stahl, Bastian; and Stöter, Maximilian, "Becoming a Product-Service System Provider - A Maturity Model for Manufacturers" (2021). Wirtschaftsinformatik 2021 Proceedings. 2. https://aisel.aisnet.org/wi2021/TDigitalServices/Track07/2

This material is brought to you by the Wirtschaftsinformatik at AIS Electronic Library (AISeL). It has been accepted for inclusion in Wirtschaftsinformatik 2021 Proceedings by an authorized administrator of AIS Electronic Library (AISeL). For more information, please contact elibrary@aisnet.org. 


\title{
Becoming a Product-Service System Provider - A Maturity Model for Manufacturers
}

\author{
Björn Häckel ${ }^{1}$, Rocco Huber ${ }^{2}$, Bastian Stahl ${ }^{1}$, and Maximilian Stöter ${ }^{2}$ \\ ${ }^{1}$ FIM Research Center, University of Applied Sciences Augsburg \\ Project Group Business \& Information Systems Engineering of the Fraunhofer FIT, \\ Augsburg, Germany \\ \{bjoern.haeckel,bastian.stahl\}@fim-rc.de \\ ${ }^{2}$ FIM Research Center, University of Augsburg \\ Project Group Business \& Information Systems Engineering of the Fraunhofer FIT, \\ Augsburg, Germany \\ \{rocco.huber,maximilian.stoeter\}@ fit.fraunhofer.de
}

\begin{abstract}
For the manufacturing industry, exploiting the opportunities of digital transformation often implies the strategic development from being a manufacturer of pure physical products to one providing Product-Service Systems (PSS). In literature, PSS can be distinguished in different types, which differ substantially in their configuration of the underlying business model. However, since distinct PSS types require different organizational capabilities, the transformation toward a PSS provider is a challenge for managers. To provide guidance, scientific and professional literature mostly focuses on selected aspects. Though, a holistic consideration of relevant capabilities for the respective PSS type remains untapped. Against this backdrop, we developed a PSS Maturity Model (PSSMM) to guide organizations in developing appropriate capabilities. To provide an integrated view, the PSSMM refers to 5 focus areas, 20 capability dimensions, and associated capabilities. To develop and evaluate our model, we used the well-known approach of Becker et al. [1].
\end{abstract}

Keywords: Product-Service Systems, Maturity Model, Industry, Digital Transformation

\section{Introduction}

In the context of digital transformation in production, the development of ProductService Systems (PSS) represents a well-established strategy for manufacturing companies to harness the various opportunities associated with digitalization. To tap new revenue pools and differentiate themselves against competitors, manufacturers are working on enriching their physical products with digital services to increase customer utility $[2,3]$. PSS not only enable a higher degree of customization and product quality but also allow for novel value propositions and new data-driven business models (BM) [4]. For instance, models such as Rolls-Royce's "power-by-the-hour" for aircraft 
engines [5] or Ricoh's "pay per page green" for printing services [6] are examples of successful PSS implementations. Especially for manufacturers, digitalization is a significant driver for PSS [7]. This is demonstrated by the "pay-per-part model" of the German machine manufacturer Trumpf, which provides its customers with laser sheet metal processing without having them to buy or lease equipment [8]. Digital technologies enable novel value propositions and services such as remote and automatic access to machine statuses, proactive detection of failures, and success measurement, facilitating PSS [9]. As physical products often form the core of the existing BM, especially for established companies and market incumbents, these companies are maturing toward more servitization [10].

Hence, along with the increasing degree of servitization, the literature distinguishes three established PSS types: product-, use-, and result-oriented PSS [4, 11, 12]. Challenges arise as the three types of PSS require different capabilities within the organization. The complexity of designing, implementing, and operating these integrated product-service bundles requires holistic guidance on which capabilities need to be developed across organizational departments and levels.

In order to guide organizations in the identification, prioritization, and development of relevant capabilities, Maturity Models (MM) have proven to be a useful management tool [13]. As research on PSS is mature [14], MMs dealing with PSS or service orientation already exist (e.g., Exner et al. [15], Gudergan et al. [16]). Further, MMs in the context of PSS focus on specific issues such as IS support for PSS [17], sustainability through hybrid solutions [18], or for the service development process related to PSS [19]. Nevertheless, existing literature hitherto neglects to bring together the established PSS types with corresponding capabilities. On the one hand, this makes it difficult for organizations to assess their maturity level to meet the desired PSS type. On the other hand, the existing models do not provide a holistic perspective on capabilities for a targeted PSS type.

Since the existing literature does not offer a combined view on PSS types and corresponding capabilities, we raised the following research question (RQ): What capabilities do organizations need to develop to offer a certain type of PSS?

To address this research gap, we developed and evaluated the PSS Maturity Model (PSSMM) and followed the well-known procedure model of Becker et al. [1]. The paper is structured as follows, in Section 2, we summarize relevant literature on PSS, MMs, and elaborate on related work for PSS-specific MMs. In Section 3, our research methodology is outlined, and in Section 4, we present essential design decisions and our developed PSSMM. Next, in Section 5, we summarize the pre-evaluation with IS scholars. At the end, Section 6 concludes this work with our contributions, limitations, and the outlook for further research. 


\section{Theoretical Background and Related Work}

\subsection{Product-Service Systems}

There are different terms for PSS in literature, e.g., Industrial Hybrid Offerings and Solutions [2], whereby PSS has become the commonly used expression [14]. Also, there are several definitions of PSS in the literature (e.g., Mont [20], Guidat et al. [21]). Yet, PSS are often defined as a type of BM that integrates bundles of products (tangible component) and services (intangible component) aiming at offering more complete solutions and thereby increasing customer utility [3, 12]. Besides, concepts such as Servitization and Hybrid Value Creation are often named in this context. Servitization describes the transformational process of moving from a product-oriented to a serviceoriented BM for offering product-centric system solutions [2, 12]. In contrast, Hybrid Value Creation refers to the process of creating added value through the combination of products and services [22]. To sum up, PSS can be seen as the operational (Hybrid Value Creation) outcome and the transformational process (Servitization).

Also, PSS are often referred to as the trend of servitization in the manufacturing industry [12] and are associated with closer customer contact, more stable revenue streams, and improved resource utilization [22]. Some work on PSS follows the understanding and perspective of Service(-dominant) Logic [23] and focus on the cocreation of value between the service provider and customer. Consequently, they define PSS as Service Systems [24]. This may especially be true for mature PSS types that are close to a pure service focused BM. However, this definition neglects companies with a product-oriented PSS type. Therefore, we argue that our work's scope mainly addresses manufacturers that are driving forward service provision. The underlying definition of PSS refers to a BM perspective that defines the value proposition through a combination of the product and connected services and whereby the focus on either the product or services shifts with the responding PSS type.

For PSS, three main types are generally admitted in the literature: (a) productoriented, (b) use-oriented, and (c) result-oriented PSS [10, 25]. These categories have established themselves in the literature (e.g., Raddats et al. [26], Weking et al. [12]), are used in different contexts (e.g., for BM archetypes [27, 28]), and are of importance for this work as we build our maturity levels upon them. For (a) product-oriented PSS, the BM is mainly focused on selling products, and only some additional services are added (e.g., maintenance services) [25]. With (b) use-oriented PSS, a product's use or availability is sold [10]. An example of use-oriented PSS is Hilti's fleet management offering, a global business partner offering construction tools. Here, Hilti provides a comprehensive bundle of products and complementary services instead of just selling tools. In doing so, Hilti improves fleet transparency, reduces idle time, and simplifies budgeting for customers, while Hilti profits from higher customer loyalty and interaction as a strategic enabler for growth [29]. And with (c) result-oriented PSS, the customer and the supplier agree in advance on the result to be delivered, and the customer only pays for that [25]. An example of this PSS-type is the cooperation of Trumpf, a German industrial machine manufacturing company, and Munich RE, a globally operating reinsurance company. The jointly developed 'pay-per-part model' 
enables customers to use a full-service laser machine without buying or leasing any equipment. Instead, customers pay a previously agreed price for each part in a predefined quality, allowing them to avoid massive up-front investments, minimize resources for maintenance tasks, and make their production processes more flexible [8]. Moving from a product- toward a use- or result-oriented PSS, a customer's need is formulated in more abstract terms. It offers new paths for customization [25], which is enabled by developments in digital technologies (e.g., cloud and edge computing), offering a continuous connection to products and customers [20]. Further, the revenue models and pricing strategies in these PSS types are entirely different, changing from single purchases to constant payment models related to the product's use or result [22]. Therefore, the transformation from being a product manufacturer to becoming a PSS provider calls for far-reaching changes within the organization and especially for new capabilities to be developed.

\subsection{Organizational Capabilities and Maturity Models}

The resource-based view defines organizations as configurations of resources [30]. Competitive advantage and long-term performance enhancement can be accomplished by providing valuable, unique, inimitable, and non-substitute resources [30] that consist of both assets and capabilities [31]. In this paper, we define capabilities as an organizational entity's ability to perform certain activities to achieve a particular outcome [32]. MMs reflect how organizational capabilities develop [33] while assessing and leading the continuous improvement of various organizational capabilities [34], such as technology, practices, or knowledge in a particular domain [13]. Thus, MMs are instruments to assess the maturity in a specific area by conceptually dividing the presumed development of maturity into different phases [33]. Maturity thereby refers to the status of being ready or complete, and the respective maturity level increases with increasing capabilities [1]. In practice, MMs have high relevance and are widely utilized as a management tool [35] that facilitate planning and stepwise capability development [13] and also improve the decision-making regarding organizational development [34]. In the Information Systems (IS) and Information Technology (IT) domain, MMs are often used either as guidance for continuous improvement or as an assessment tool for self- or third-party evaluation [33, 34]. Besides, there are different types of MMs in literature, including descriptive (status quo assessment and potential target state derivation), comparative (benchmarking), and prescriptive $M M s$ (enabling roadmap development and suggesting measures for achieving it). Also, combinations of these types exist, as these different model types represent consecutive stages in a MM's evolution [33, 36].

The general structure of MMs is characterized by a sequence of discrete stages [13] reflecting the expected or desired development path from an initial to a potential target state [1]. MMs are usually conceptualized as matrices, including maturity stages on the one and dimensions (e.g., capabilities) on the other axis [36]. To structure capabilities, focus areas can be defined, representing domain-specific capability areas that describe different aspects of the corresponding topic [34] and provide more detail by describing specific capabilities as subcategories (i.e., Capability Dimensions). On the other axis, 
the maturity levels describe the phases of development arranged in sequential order from the lowest stage of maturity to the highest [36]. The number of maturity stages between the initial and target state is not prescribed and varies in existing MMs. However, most MMs use between four to six stages [36]. Also, MM types can furthermore be distinguished into staged, continuous, and focus area MMs [37, 38]. These reflect different ways of assigning capabilities to maturity stages. Thereby, staged MMs require an assignment of capabilities to exactly one maturity stage. Continuous MMs require the specification of capabilities for all maturity stages. In contrast, focus area MMs inductively derive maturity stages per capability area, where each capability area has its number of specific maturity stages.

\subsection{Related MMs in the Field of PSS}

As the PSS domain is a mature research area and research has been conducted here for over 20 years [14], several MMs already exist in this research field. MMs, with a focus on PSS, address the increasing service orientation in the sense of maturing from traditional product sales to PSS (e.g., Rapaccini et al. [19], Gudergan et al. [16], Karni et al. [39], Exner et al. [15]). Rapaccini et al. [19] created a MM for the new service development process related to PSS. Gudergan et al. [16] introduce their Business Transformation Readiness Assessment - a MM to assess the readiness for PSS. Karni and Kaner [39] present a Process Capability and Enterprise Maturity Model focusing on PSS. Exner et al. [15] developed a PSS capability self-assessment tool for companies named Product-Service-Change. Other MMs in the context of PSS and servitization address more specific issues concerning IS support for PSS [17, 40], service engineering [41], or sustainability through hybrid solutions [18]. There are already several MMs in the research field of PSS. Still, to the best of our knowledge, there is no MM with a holistic perspective on the organization and that combines its maturity levels with the three different types of PSS, including product-, use-, and resultoriented PSS. Thus, existing MMs do not allow conclusions and provide guidance on how the identified capabilities should be developed concerning an aimed, pre-defined PSS type. Our paper aims at filling this gap. Further, our PSSMM provides a multidimensional categorization for PSS capabilities and therefore provides guidance for capability development. Therefore, with this work, we propose a continuous MM that can be used for descriptive and prescriptive purposes [33].

\section{$3 \quad$ Research Methodology and Development Process}

The approach of Becker et al. [1] for the development of our MM comprises, as presented in Figure 1, eight steps that are based on design science research principles by Hevner et al. [42]. The first four phases are central to the design and development of the MM, whereas the second four cover the transfer and evaluation. All in all, this work focuses on phases 1 to 4 . The other phases will be carried out in future research. In the following, we briefly explain each phase and how we executed it: 


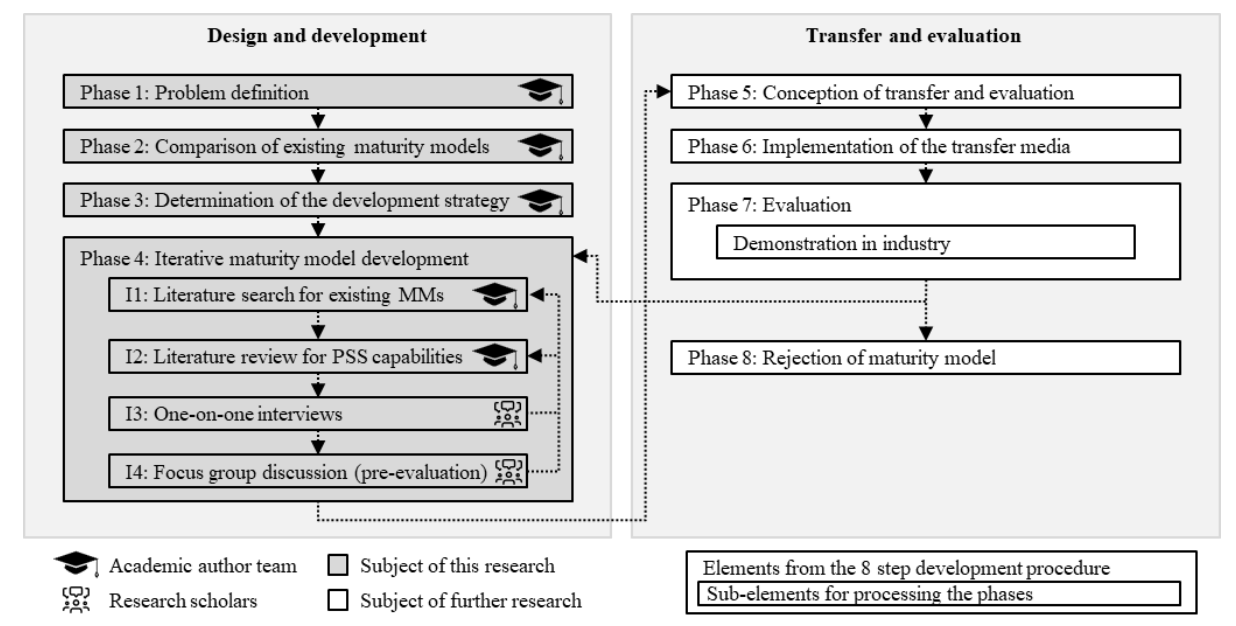

Figure 1. Applied Research Approach Based on Becker et al. [1]

Phase 1, Problem definition, examines the motivation for the particular MM and derives an appropriate RQ. We address this phase in our Introduction, where the topic's relevance and the need for management guidance, like for our PSSMM, are outlined. Thereby, the key problem is that manufacturers face significant challenges in developing toward a PSS provider. While existing MMs for PSS neglect a holistic perspective on the organization, we propose our PSSMM to fill this gap.

Phase 2, Comparison of existing $M M$ s, thematizes the relevance of developing a MM by pointing toward the research gap. The lack of existing approaches is initially addressed in the Introduction and then outlined at the end of the Theoretical Background (see Section 2.3.).

Phase 3 is the Determination of the development strategy. Becker et al. [1] differentiate between four strategies, i.e., (1) design of a new model, (2) enhancement of an existing model, (3) combination of models to form a new one, and (4) the transfer of existing models to new application domains. As mentioned in the Theoretical Background, there is no MM in the literature that addresses our purpose and RQ. In this work, we developed a novel MM (strategy 1) as an artifact based on the insights of existing MMs and additional literature, as neither an existing model was close enough to be enhanced (strategy 2) nor existing models combined (see below) could fulfill the research question.

Within Phase 4, the Iterative MM development, we - additionally to Becker et al. [1] - considered van Steenbergen et al. [43], as they recommend using a multimethodological approach for the development of dimension-specific development paths. To assess and integrate different knowledge sources for this manifold topic, we included a literature search and interviews with research scholars [33, 43]. The following figure presents how the development phase of the PSSMM was carried out in four iterations. 


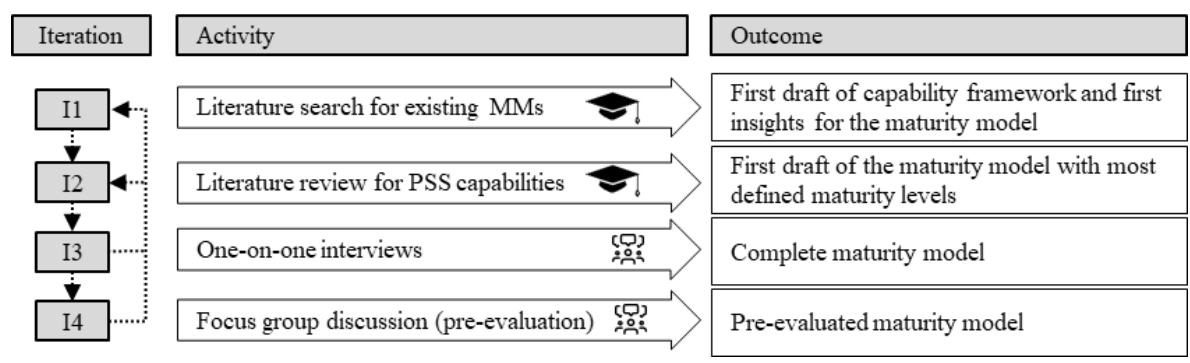

Figure 2. Applied Iterations within the Development Phase

Within Iteration one, the literature search, we started by identifying existing MMs focused on PSS and related research streams as recommended by Becker et al. [1]. With this iteration, we identified first context-related MMs for PSS and scrutinized those for capabilities and maturity levels related to our research gap. For this, we performed a search on Google Scholar with the following search string: "product-service system*" OR "PSS" OR "hybrid product*" OR "servitization" OR "hybrid value creation" $A N D$ "maturity model". As a result, we found 15 papers related to MMs for PSS, which came into consideration, e.g., Rapaccini et al. [19], Gudergan et al. [16], Karni and Kaner [39], Exner et al. [15]. To understand and build upon existing work, as recommended by Becker et al. [1], we compared the MMs and partly included them in our MM by identifying relevant capabilities for PSS. Within this bottom-up approach, we identified 180 capabilities for PSS from related MMs. After coding and clustering these capabilities, we came up with 18 capability dimensions within this iteration. We chose this approach because we wanted to develop the MM without being influenced by the different existing MMs on PSS (e.g., on sustainability) and tailor our dimensions toward our research gap, taking a PSS-type specific and holistic view. The interim result here was the first draft of a capability framework with capability dimensions and first insights for the definition of some maturity levels.

Next, with Iteration two, we carried out a literature review for PSS and corresponding capabilities following vom Brocke et al. [44] to ensure that the body of knowledge is covered by existing MMs on PSS but also on recent and domain-specific work. Hence, we applied this by assessing domain-related databases, i.e., ScienceDirect, EBSCOhost, and AISeL, with the following search string: "productservice system*" OR "PSS" OR "hybrid product*" AND "industrial" AND "capabilit*". Thereby, we reviewed 62 articles to identify PSS capabilities. Furthermore, we finished with a forward and backward search to screen the field of research and completed the maturity levels. After carefully reading and screening these publications, we worked out and coded another 72 capabilities from this general PSS literature. Here, 19 capability dimensions were identified. As a result, the first iteration's draft was complemented with the capability dimensions and maturity levels found in literature.

In these first two iterations, all in all, 252 capabilities $(=180+72)$ were found and processed (coded and clustered), which resulted in 37 capability dimensions (18 from existing MMs and 19 from PSS literature). After reducing the duplicates and 
summarizing similar ones, 20 capability dimensions were finally derived. As we developed a continuous MM, the definition of all maturity levels, including different characteristics, is required to outline each capability dimension's maturation along all stages. We proceeded by using the literature and more specified capabilities.

Iteration three - after developing the second version of the PSSMM and intensively discussing it within the author team, we conducted two interviews with scholars from the IS domain for the understanding and relevance of its focus areas, capability dimensions, as well as each level of maturity. One is specialized in MM development, and the other in digital transformation strategies for manufacturers. The interview partners are summarized in Table 1 (Int 1 and Int 2). Afterward, each proposed model adjustment was critically discussed within the author team and cross-checked with supporting work in literature before including the feedback into the PSSMM.

Iteration four - after reaching consensus among the authors about the maturity of the model, as the interviews brought no significant insights to the MM and instead helped to sharpen the identified capabilities, the MM was pre-evaluated in a focus group discussion with nine domain-specific scholars specialized on PSS and related capabilities (Int 3 in Table 1). Thereby, we used the proposed evaluation criteria of Becker et al. [1], i.e., comprehensiveness, consistency, and problem adequacy. The discussion did not lead to advanced adjustments of the model and underpinned its saturated maturity. This pre-evaluation is addressed in detail in Section 5.

Table 1. Interview Partner

\begin{tabular}{|l|l|l|l|}
\hline Interview ID & Type & Expertise & Experience \\
\hline Int 1 & $\begin{array}{l}\text { One-on-one Interview } \\
(\mathrm{n}=1)\end{array}$ & $\begin{array}{l}\text { Transformation strategies } \\
\text { for manufacturers }\end{array}$ & $\begin{array}{l}\text { Junior researcher } \\
(1-2 \text { years in this field })\end{array}$ \\
\hline Int 2 & $\begin{array}{l}\text { One-on-one Interview } \\
(\mathrm{n}=1)\end{array}$ & $\begin{array}{l}\text { Maturity models and } \\
\text { organizational capabilities }\end{array}$ & $\begin{array}{l}\text { Senior researcher } \\
(>3 \text { years in this field) }\end{array}$ \\
\hline $\begin{array}{l}\text { Int 3 } \\
\text { (pre-evaluation })\end{array}$ & $\begin{array}{l}\text { Focus group discussion } \\
(\mathrm{n}=9)\end{array}$ & $\begin{array}{l}\text { Domain focus on Industry } \\
4.0 \text { and PSS BM }\end{array}$ & $\begin{array}{l}\text { PhD students and senior } \\
\text { scholars }\end{array}$ \\
\hline
\end{tabular}

Phases 5 to 8 are, as mentioned before, not the object of this paper and, thus, the subject of further research. After developing the model, it needs to be tested in a realworld context and evaluated with industry experts for relevance and rigor, including validity and reliability [33]. Also, for guaranteeing broad applicability, the model must be made available in a more general way to investigate its generalizability [1] (phase 5). Next, further evaluations and improvements on wider acceptance are conducted (Phase 6,7), and finally, a decision on the acceptance or the rejection of the model is made (Phase 8).

\section{$4 \quad$ Product-Service Systems Maturity Model}

In the following, we present our PSSMM with its overarching structure by first elaborating on pathbreaking design decisions and afterward outlining each focus area and its associated capability dimensions. At the end of this section, we present the whole PSSMM with its corresponding maturity levels. We developed a continuous MM $[33,37]$ along the PSS types of Tukker $[11,25]$. This design allows reflecting the non- 
linearity of transformation processes (i.e., being at different maturity stages for different capability dimensions). A certain maturity level thereby describes how a capability in this capability dimension is typically developed within this step (i.e., type of PSS). For the maturity levels, we set the 'pure product' view as the initial stage (1.) that reflects a common starting point of a transformation toward PSS. The three main PSS types $[10,11]$ represent the remaining maturity levels of our model: product- (2.), use- (3.), and result-oriented PSS (4.). We have arranged the levels 1 to 4 next to each other according to their maturity toward servitization. In doing so, we guide organizations in further developing the needed organizational capabilities (i.e., for service deployment) toward a target type of PSS and do not refer to the commonly used generic maturity levels in existing MMs on PSS (e.g., Rapaccini et al. [19]). As with almost all MMs, the definition of a target state is not primarily dependent on the pursuit of higher levels of maturity, but rather on organization-specific (e.g., customer requirements) as well as economic (e.g., budget) factors. Also, certain PSS types can be skipped or different PSS types can be implemented within the same company, e.g., different markets or customer segments. Further, and in contrast to existing maturity models (e.g., Rapaccini et al. [19], Karni and Kaner [39], Gudergan et al. [16]), our PSSMM aims to demonstrate relevant capabilities for the respective PSS types. Thus, each column offers a detailed specification of the required capabilities for the corresponding PSS type. To take a holistic perspective on the organization and follow Cleven et al. [37], our MM addresses five focus areas: Strategy, Culture, Structure, Practices, and IT. Those were successfully used for other domain-specific MMs before, e.g., Enterprise Architecture Management [45] or Business Process Management [33]. Table 2 lists the focus areas' definitions based on Cleven et al. [37] and Rosemann and vom Brocke [46] and represent relevant capability areas for organizational capabilities.

Table 2. Five Focus Areas for Capability Development in Organizations

\begin{tabular}{|l|l|}
\hline Focus Area & Definition \\
\hline Strategy & $\begin{array}{l}\text { Strategy comprises the vision of how an organization creates value and develops } \\
\text { toward a defined target state. }\end{array}$ \\
\hline Culture & Culture covers the collective values and behaviors of individuals and teams. \\
\hline Structure & $\begin{array}{l}\text { Structure comprises the way an organization is shaped and interacts with its } \\
\text { environment to achieve its goals. }\end{array}$ \\
\hline Practices & $\begin{array}{l}\text { Practices cover key activities, responsibilities, methods, mechanisms, routines, } \\
\text { competencies, and processes. }\end{array}$ \\
\hline IT & $\begin{array}{l}\text { IT comprises technical solutions that support and enable the operation of the } \\
\text { organization but also the design, implementation, execution, and control of activities } \\
\text { and objectives. }\end{array}$ \\
\hline
\end{tabular}

The five focus areas represent action fields for organizations that need to be further specified. This is achieved by assigning our capability dimensions to these focus areas. The PSSMM, presented in Table 3, thus provides a holistic overview of relevant capabilities, which we assign to 20 capability dimensions to evolve toward one of the three main types of PSS.

The focus area Strategy describes to which extent the organization focuses on enriching its value creation with services until service is at the core of their business model (Service Focus) [18]. This strategy shift creates the necessary foundation for an 
organization to develop and implement a successful PSS. Customer centricity, therefore, becomes an essential part of business strategy and value creation (Customer Involvement $[15,25]$. Furthermore, a PSS-driven vision is pursued by allocating human and financial resources (Resource Allocation for PSS) [10, 19]. The PSS strategy determines the direction in which an organization should thrive and is, therefore, a signpost for the resulting focus areas.

As a second focus area, Culture comprises how employees work together (Work Culture) $[47,48]$ and how the organization's PSS vision is committed by the employees (Employee-committed PSS Vision) [16, 17]. This capability dimension is directly enabled by 'Resource Allocation for PSS' from Strategy and underpins that the entire workforce must support the PSS-vision. To successfully master PSS, relevant soft and hard skills need to be developed throughout the organization (Skill Training) [49], e.g., data analytics or leadership.

Regarding the organization's Structure, PSS require distinct changes in how the product or PSS is marketed and what channels are used to deliver the value (Channels and Sales). Here, the product itself becomes a new and essential channel, especially in mature PSS types [50, 51]. Also, through the establishment of new channels, extensive value-added networks, and the deep integration of the product into the customer's processes, the organization's boundaries become blurred as external partners are increasingly integrated into business processes (Partner Integration) $[10,15,20]$. As the business model depends less on the sale of the product and focuses on services, the organization must manage the change of its income, changing from one-time product purchases to continuous payments for services (Capital Management) [10, 25].

The focus area Practices consist of six capability dimensions. The first addresses how an interaction with the customer has to be initialized regarding services (Customer Interaction and Service Initiative) [3, 52]. Mature PSS go in line with increasing customer interaction and responsibility for the performance of the product. The next capability dimension addresses how to design and enable high quality of PSS. The specificity of the methods and tools used increases with mature PSS and gains importance for innovation and product management (PSS Design Methods and Tools) $[53,54]$. As mature PSS have a strong focus on product availability and performance for the customer, feedback on the product and its performance are a crucial factor on the practice level. Therefore, Product Performance Measurement and Feedback Systems become increasingly relevant for the provision of additional services or advice, but also regarding the pricing of mature PSS [19, 25]. Automated Service Offering is crucial to ensure the product and service availability, especially for mature PSS [55, 56]. In this context, mature PSS also request the ability to develop and offer suitable pricing models and customer-individual prices that are increasingly distinguished by performance-oriented payment structures (Pricing Mechanism) [4, 57]. Also, Life Cycle Management becomes essential to accompany the customer holistically before, during, and after using the product [25].

IT, at the bottom of our PSSMM, acts as the foundation for enabling the development and operation of PSS. First, the Role of IT determines whether IT only supports business or takes over an enabling role regarding the organization's actions and objectives [58]. Due to the increasing collection and exchange of valuable data 
Table 3. The PSSMM

\begin{tabular}{|c|c|c|c|c|c|}
\hline \multirow{2}{*}{$\begin{array}{c}\text { Focus } \\
\text { Area }\end{array}$} & \multirow{2}{*}{$\begin{array}{l}\text { Capability } \\
\text { Dimension }\end{array}$} & \multicolumn{4}{|c|}{ Maturity Level } \\
\hline & & 1. Pure Product & 2. Product-oriented PSS & 3. Use-oriented PSS & 4. Result-oriented PSS \\
\hline \multirow{3}{*}{ 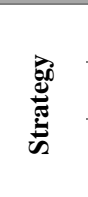 } & Service Focus & $\begin{array}{l}\text { Focus on the physical product; no } \\
\text { additional services }\end{array}$ & $\begin{array}{l}\text { Limited focus on PSS; additional services like consulting, } \\
\text { maintenance, or recycling }\end{array}$ & $\begin{array}{l}\text { Focus on PSS; warranty of the availability of the physical } \\
\text { product along with services }\end{array}$ & $\begin{array}{l}\text { Focus on mature PSS as core business model; highly integrated product- } \\
\text { service bundles to offer result as a service }\end{array}$ \\
\hline & $\begin{array}{c}\text { Customer } \\
\text { Involvement }\end{array}$ & $\begin{array}{l}\text { No or little involvement to design and } \\
\text { evolve the physical product }\end{array}$ & $\begin{array}{l}\text { Growing involvement to design and evolve the product and } \\
\text { additional services }\end{array}$ & $\begin{array}{l}\text { Increasing cooperation with and integration of the customer } \\
\text { into PSS design processes }\end{array}$ & $\begin{array}{l}\text { Partner-like collaboration and intensive communication for PSS } \\
\text { development }\end{array}$ \\
\hline & $\begin{array}{l}\text { Resource } \\
\text { Allocation for } \\
\text { PSS }\end{array}$ & $\begin{array}{l}\text { No budget for PSS development and } \\
\text { implementation }\end{array}$ & $\begin{array}{l}\text { Little effort for creating additional services to the product; ad } \\
\text { hoc investments in organizational changes }\end{array}$ & $\begin{array}{l}\text { Medium effort for creating well-functioning PSS; continuous } \\
\text { investments }\end{array}$ & $\begin{array}{l}\text { Great efforts to achieve a high-performance PSS; substantial and } \\
\text { continuous investments }\end{array}$ \\
\hline \multirow{3}{*}{ 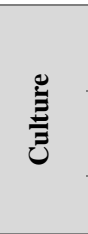 } & Work Culture & $\begin{array}{l}\text { Focus on product-related solutions; } \\
\text { independent work or partly in } \\
\text { homogenous teams }\end{array}$ & $\begin{array}{l}\text { Focus on product-related solutions and on easy-to-implement } \\
\text { services; occasional work in interdisciplinary teams }\end{array}$ & $\begin{array}{l}\text { Solution-oriented in terms of both products and services; } \\
\text { usually work in interdisciplinary teams }\end{array}$ & $\begin{array}{l}\text { Solution-oriented for PSS; team-oriented, cross-team, } \\
\text {-domain, and -organizational work, continuous exchange with customers } \\
\text { and value-added partners }\end{array}$ \\
\hline & $\begin{array}{c}\text { Employee- } \\
\text { committed PSS } \\
\text { Vision }\end{array}$ & $\begin{array}{l}\text { Product-oriented way of thinking; } \\
\text { working for developing and selling } \\
\text { physical products }\end{array}$ & $\begin{array}{l}\text { Product-oriented way of thinking; working for offering } \\
\text { complementary services to the product }\end{array}$ & $\begin{array}{l}\text { Thinking in terms of customer usage; working for providing } \\
\text { PSS solutions with a higher level of service integration }\end{array}$ & $\begin{array}{l}\text { Thinking in terms of customer results; working for delivering result as a } \\
\text { service }\end{array}$ \\
\hline & Skill Training & $\begin{array}{l}\text { No training or further education } \\
\text { regarding PSS skills }\end{array}$ & $\begin{array}{l}\text { Occasional in terms of PSS development, training for } \\
\text { product-related consultation }\end{array}$ & $\begin{array}{l}\text { Selective training courses on specific topics for PSS } \\
\text { development and implementation }\end{array}$ & $\begin{array}{l}\text { Structured training courses on all relevant PSS topics like development, } \\
\text { implementation, sales, customer contact, leadership, and management }\end{array}$ \\
\hline \multirow{3}{*}{ 窇 } & $\begin{array}{l}\text { Channels and } \\
\text { Sales }\end{array}$ & $\begin{array}{l}\text { Traditional and web-based channels for } \\
\text { product sales }\end{array}$ & $\begin{array}{l}\text { Traditional and web-based channels for product and service } \\
\text { sales }\end{array}$ & $\begin{array}{l}\text { Traditional and web-based channels or product as point of } \\
\text { sale }\end{array}$ & $\begin{array}{l}\text { Traditional and web-based channels and product as point of sale for } \\
\text { integrated view on results }\end{array}$ \\
\hline & $\begin{array}{l}\text { Partner } \\
\text { Integration }\end{array}$ & $\begin{array}{l}\text { Only suppliers as value-adding partners; } \\
\text { clear organizational boundaries }\end{array}$ & $\begin{array}{l}\text { Additional value-adding partners for service-creation and } \\
\text { initial involvement of and cooperation with customer as } \\
\text { partner }\end{array}$ & $\begin{array}{l}\text { Blurring of boundaries between company and suppliers as } \\
\text { well as service-creation involved partners; close cooperation } \\
\text { with customer as partner }\end{array}$ & $\begin{array}{l}\text { Strong collaboration and integration of value-added partners and customer } \\
\text { for PSS co-creation; company is deeply integrated into customers' } \\
\text { processes and business model }\end{array}$ \\
\hline & $\begin{array}{c}\text { Capital } \\
\text { Management }\end{array}$ & $\begin{array}{l}\text { Bearing all costs until point of sale; } \\
\text { management of one-time payments for } \\
\text { each product sale }\end{array}$ & $\begin{array}{l}\text { Bearing all costs until point of sale; management of one-time } \\
\text { payment for product and demand-driven service provision } \\
\text { income }\end{array}$ & $\begin{array}{l}\text { Bearing of production and development costs for products } \\
\text { and services until a pre-defined point of time; continuous } \\
\text { payments for usage }\end{array}$ & $\begin{array}{l}\text { until end of life cycle; continuous and success- } \\
\text { ation of the PSS }\end{array}$ \\
\hline \multirow{6}{*}{ 芯 } & $\begin{array}{c}\text { Customer } \\
\text { Interaction and } \\
\text { Service Initiative }\end{array}$ & $\begin{array}{l}\text { Interaction focuses on product purchase } \\
\text { and emerging operation problems; } \\
\text { customer is responsible for operations }\end{array}$ & $\begin{array}{l}\text { Interaction is driven by the customer; interactions are pre- } \\
\text { defined in the service contract; mostly topic-driven services } \\
\text { related to maintenance }\end{array}$ & $\begin{array}{l}\text { PSS provider initiates services and is responsible for ensuring } \\
\text { the perpetual availability; planned interactions }\end{array}$ & $\begin{array}{l}\text { Proactive and automated service interaction; connected through pre- } \\
\text { defined touch points and processes; result as continuously monitored } \\
\text { parameter for service initiative }\end{array}$ \\
\hline & $\begin{array}{l}\text { PSS Design } \\
\text { Methods and } \\
\text { Tools }\end{array}$ & $\begin{array}{l}\text { No approach for service or PSS } \\
\text { development; }\end{array}$ & $\begin{array}{l}\text { General (management) approaches for product; partial use of } \\
\text { PSS methods and tools }\end{array}$ & $\begin{array}{l}\text { Selected approaches and formalized development processes } \\
\text { for PSS; appropriate tools for development and } \\
\text { implementation }\end{array}$ & $\begin{array}{l}\text { Company-specific and individualized PSS approaches plus fast } \\
\text { development cycles and prototyping; continuous improvement and use of } \\
\text { methods }\end{array}$ \\
\hline & $\begin{array}{l}\text { Product } \\
\text { Performance } \\
\text { Measurement }\end{array}$ & $\begin{array}{l}\text { No need for measuring product } \\
\text { performance; only measuring product } \\
\text { quality by internal tests }\end{array}$ & $\begin{array}{l}\text { No need for measuring product performance but occasional } \\
\text { insights through maintenance services; measuring product } \\
\text { quality in order to provide advice and guidance to customers }\end{array}$ & $\begin{array}{l}\text { Meast } \\
\text { guarar }\end{array}$ & $\begin{array}{l}\text { Well-defined measures and feedbacks are systematically u } \\
\text { payments, maintenance, and new service development }\end{array}$ \\
\hline & $\begin{array}{c}\text { Automated } \\
\text { Service Offering }\end{array}$ & No service provision & $\begin{array}{l}\text { Almost no aut } \\
\text { provision }\end{array}$ & urtly automated or modularized services are provided & $\begin{array}{l}\text { Most services with the customer or value-creation partners are automated } \\
\text { and/or modularized; optimization toward minimizing human-interaction in } \\
\text { the service process }\end{array}$ \\
\hline & $\begin{array}{c}\text { Pricing } \\
\text { Mechanism }\end{array}$ & $\begin{array}{l}\text { Fixed one-time payment (pay for } \\
\text { product) }\end{array}$ & $\begin{array}{l}\text { One-time payr } \\
\text { for product or }\end{array}$ & $\begin{array}{l}\text { Continu } \\
\text { availabi }\end{array}$ & $\begin{array}{l}\text { Customer-specific, result-based payment based on service level agreement } \\
\text { (pay on production) }\end{array}$ \\
\hline & $\begin{array}{l}\text { Life Cycle } \\
\text { Management }\end{array}$ & $\begin{array}{l}\text { Development, production, sale, and } \\
\text { shipment; no responsibility for operation }\end{array}$ & $\begin{array}{l}\text { Development, production, sale, and shipment; no } \\
\text { responsibility for operation but reactive provision of services }\end{array}$ & $\begin{array}{l}\text { Development, production, sale, shipment, maintenance, and } \\
\text { usage phase; responsible for guaranteeing the usability of the } \\
\text { product }\end{array}$ & $\begin{array}{l}\text { Managing everything until the end of the product life cycle; responsible } \\
\text { for delivering results and productivity }\end{array}$ \\
\hline \multirow{5}{*}{$\Xi$} & Role of IT & $\begin{array}{l}\text { IT as supporting function; intra- } \\
\text { organizational focus }\end{array}$ & $\begin{array}{l}\text { Supporting function, partly as driver of value creation and } \\
\text { change; intra-organizational focus }\end{array}$ & $\begin{array}{l}\text { IT as an enabler and diver for value creation and change; } \\
\text { enabler of product-availability; inter-organizational focus }\end{array}$ & $\begin{array}{l}\text { IT as an enabler and driver for value cre } \\
\text { enhanced product-performance, inter-org }\end{array}$ \\
\hline & $\begin{array}{l}\text { IT Security and } \\
\text { Compliance }\end{array}$ & $\begin{array}{l}\text { Security of highly critical assets; isolated } \\
\text { IT security activities }\end{array}$ & $\begin{array}{l}\text { Security of highly critical assets and initially also of external } \\
\text { processes }\end{array}$ & Intra- and inter-organizational IT security activities & $\begin{array}{l}\text { Intra- and inter-organizational IT security activities; security by design in } \\
\text { product development process }\end{array}$ \\
\hline & $\begin{array}{l}\text { Connectivity and } \\
\text { Data Access }\end{array}$ & No access to product after point of sale & $\begin{array}{l}\text { Indirect, situational data access to customer; possible manual } \\
\text { data exchange }\end{array}$ & $\begin{array}{l}\text { Continuous interconnectivity; mainly reading rights; } \\
\text { connectivity of the product is a substantial component }\end{array}$ & $\begin{array}{l}\text { Continuous interconnectivity; full access to product; connectivity of the } \\
\text { product is a substantial component }\end{array}$ \\
\hline & Data Collection & No collection of customer's product data & Reactive and manual collection of data & Partly automated collection of data from the customer & Highly automated collection of data \\
\hline & Data A & $\begin{array}{l}\text { No analysis of product usage or } \\
\text { descriptive analysis of internal product } \\
\text { testing }\end{array}$ & $\begin{array}{l}\text { Descriptive and diagnostic analysis of product data; initially } \\
\text { for service provision }\end{array}$ & $\begin{array}{l}\text { Diagnostic and predictive analysis of product data; focus to } \\
\text { keep promise of availability }\end{array}$ & ation of result \\
\hline
\end{tabular}


regarding PSS value chains and business ecosystems, IT Security and Compliance activities need to enable holistic IT security concepts across organizational boundaries [59]. Especially result-oriented PSS depend on a continuous connection and data availability for performance measurement or determination of payments [17, 60]. Therefore, Connectivity and Data Access were added as an IT-capability. To provide data-driven services, e.g., predictive maintenance, relevant product data needs to be collected (Data Collection) [17] and analyzed (Data Analysis) [57], so that, e.g., necessary key performance measures can be created that are crucial for offering PSS.

\section{Pre-evaluation}

As recommended in the development process of Becker et al. [1], we evaluated our PSSMM using proposed evaluation criteria. We conducted a pre-evaluation of the model to anticipate a demonstration and application of the model in practice to first assess the model's quality according to recommended criteria. A comprehensive application and demonstration of the model in practice with industry experts, as proposed by Becker et al. [1], is planned to be subject to further research. Therefore, our theoretical evaluation was carried out through a focus group discussion with domain-specific scholars of the IS discipline. We used the evaluation criteria of Becker et al. [1], which are: (1) comprehensiveness, (2) consistency, and (3) problem adequacy. The focus group comprised nine research scholars with experience in PSS and MM development (see also Table 1 in Section 3).

(1) Comprehensiveness: Within the focus group, the model was perceived as comprehensive and covering essential PSS aspects. Nevertheless, we enriched several capability dimensions with some details, e.g., IT Security and Compliance with the term 'security by design' in the last maturity level of result-oriented PSS.

(2) Consistency: The focus group generally agreed on the overall consistency but objected to a few minor issues. Minor adjustments, such as eliminating non-uniform designations for the same term, e.g., 'teamwork', 'work in teams', and 'collaboration in teams', were made.

(3) Problem adequacy: The focus group discussion led to several iterations of the model, which resulted in an improved specificity for the application context. For example, we have adjusted some generic capabilities for transformational processes and specified them for the intended context of manufacturing companies that aim to offer PSS (e.g., 'project management', 'agility', and 'change management').

\section{Conclusion and Outlook}

This paper addresses the need for conceptual work to guide manufacturers in becoming PSS providers [61]. It contributes to the interplay between established PSS types and organizational capabilities, which has not yet been sufficiently addressed in literature. To fill this gap, we developed a MM for the transformation into becoming a PSS provider. To structure the MM, we used the well-established PSS types of Tukker et al. [11, 25] - product-, use-, and result-oriented PSS - often applied in literature for 
distinguishing the different types of BMs and their implications on organization or environment (e.g., Bocken et al. [27], Yang and Evans [28]). For the MM development, we followed Becker et al.'s [1] procedure model. We first searched for existing MMs (e.g., Rapaccini et al. [19], Gudergan et al. [16], Exner et al. [15]) and second conducted a literature review for PSS-specific capabilities. After, we iteratively developed the model by building upon the literature, conducting expert interviews with senior scholars, and pre-evaluated the PSSMM with domain-specific scholars by checking for the proposed evaluation criteria (i.e., comprehensiveness, consistency, problem adequacy) of Becker et al. [1] in a focus group discussion.

Our contribution is relevant for practice and research. For the latter, the PSSMM adds to descriptive and prescriptive knowledge on PSS and supplements the current discussion on PSS (e.g., Exner et al. [15], Pigosso et al. [18]). In particular, our work represents the hitherto missing link between established PSS types and corresponding capabilities. We also contribute by summarizing, structuring, and enriching current PSS literature and providing a foundation for future research on specific PSS capabilities. This work also points out that digitalization is a driver for PSS in the manufacturing industry.

On the one hand, this offers the possibility of differentiation to overcome market pressure at the product level. On the other hand, the developed model reveals at various points how digital technologies may serve as an enabler to offer PSS (e.g., connectivity and data access, customer interaction and service initiative, automated service offering). For practice, the PSSMM guides manufacturers in transforming themselves toward a certain type of PSS. Our model supports this strategic transformation by defining the needed capabilities. For example, management can use the PSSMM to evaluate their status quo and desired target state. This makes it easier for managers to assess the necessary efforts for developing needed capabilities. For the transformation process, additional management tools such as manuals or self-assessment questionnaires are needed to complement the PSSMM [1].

As any research project, this work is beset with limitations, which stimulate future research. Although this paper followed the MM development approach of Becker at al. [1], the development of our PSSMM is limited to phases 1 to 4 . To guarantee a high quality of this work, this paper built upon current and PSS-specific literature and was challenged and evaluated by domain experts in IS research. However, an evaluation with industry experts to scrutinize the PSSMM and check its completeness, real-world fidelity, and practical applicability is missing. Also, a demonstration of the PSSMM in a real-world context has not been carried out yet. Both are planned as next steps within the research project. Also, further research could provide an approach for application.

\section{References}

1. Becker, J., Knackstedt, R., Pöppelbuß, J.: Developing Maturity Models for IT Management. Bus Inf Syst Eng 1, 213-222 (2009)

2. Kowalkowski, C., Gebauer, H., Kamp, B., Parry, G.: Servitization and Deservitization: Overview, Concepts, and Definitions. Industrial Marketing Management 60, 4-10 (2017) 
3. Boehm, M., Thomas, O.: Looking Beyond the Rim of One's Teacup: A Multidisciplinary Literature Review of Product-Service Systems in Information Systems, Business Management, and Engineering \& Design. Journal of Cleaner Production 51, 245-260 (2013)

4. Baines, T., Lightfoot, H., Peppard, J., Johnson, M., Tiwari, A., Shehab, E., Swink, M.: Towards an Operations Strategy for Product-centric Servitization. Int Jrnl of Op \& Prod Mnagemnt 29, 494-519 (2009)

5. Mahut, F., Daaboul, J., Bricogne, M., Eynard, B.: Product-Service Systems for Servitization of the Automotive Idustry: A Literature Review. International Journal of Production Research 55, 2102-2120 (2017)

6. Brambila-Macias, S.A., Sakao, T., Kowalkowski, C.: Bridging the Gap between Engineering Design and Marketing: Insights for Research and Practice in product/service system design. Des. Sci. 4, 1 (2018)

7. Lerch, C., Gotsch, M.: Digitalized Product-Service Systems in Manufacturing Firms: A Case Study Analysis. Research-Technology Management 58, 45-52 (2015)

8. Munich Re: Pay-per-part: TRUMPF and Munich Re plan new business model for the manufacturing industry, https://www.munichre.com/en/company/media-relations/mediainformation-and-corporate-news/media-information/2020/2020-10-14-pay-per-part.html

9. Suppatvech, C., Godsell, J., Day, S.: The Roles of Internet of Things Technology in Enabling Servitized Business Models: A Systematic Literature Review. Industrial Marketing Management 82, 70-86 (2019)

10. Baines, T., Lightfoot, H., Evans, S., Neely, A., Greenough, R., Peppard, J., Roy, R., Shehab, E., Braganza, A., Tiwari, A., et al.: State-of-the-art in Product-service Systems. Proceedings of the Institution of Mechanical Engineers, Part B: Journal of Engineering Manufacture 221, 1543-1552 (2007)

11. Tukker, A., Tischner, U.: New Business for Old Europe: Product-service Development, Competitiveness and Sustainability. Routledge (2017)

12. Weking, J., Stöcker, M., Kowalkiewicz, M., Böhm, M., Krcmar, H.: Leveraging Industry 4.0 - A Business Model Pattern Framework. International Journal of Production Economics 225,107588 (2020)

13. Pöppelbuß, J., Röglinger, M.: What Makes a Useful Maturity Model? A Framework of General Design Principles for Maturity Models and its Demonstration in Business Process Management. In: Proceedings of the European Conference on Information Systems (ECIS), $28(2011)$

14. Li, A.Q., Found, P.: Towards Sustainability: PSS, Digital Technology and Value Cocreation. Procedia CIRP 64, 79-84 (2017)

15. Exner, K., Balder, J., Stark, R.: A PSS Maturity Self-assessment Tool. Procedia CIRP 73, 86-90 (2018)

16. Gudergan, G., Buschmeyer, A., Krechting, D., Feige, B.: Evaluating the Readiness to Transform Towards a Product-service System Provider by a Capability Maturity Modelling Approach. Procedia CIRP 30, 384-389 (2015)

17. Neff, A.A., Hamel, F., Herz, T.P., Uebernickel, F., Brenner, W., vom Brocke, J.: Developing a Maturity Model for Service Systems in Heavy Equipment Manufacturing Enterprises. Information \& Management 51, 895-911 (2014) 
18. Pigosso, D.C.A., McAloone, T.C.: Maturity-based Approach for the Development of Environmentally Sustainable Product/Service-Systems. CIRP Journal of Manufacturing Science and Technology 15, 33-41 (2016)

19. Rapaccini, M., Saccani, N., Pezzotta, G., Burger, T., Ganz, W.: Service Development in Product-service Systems: A Maturity Model. The Service Industries Journal 33, 300-319 (2013)

20. Mont, O.K.: Clarifying the Concept of Product-service System. Journal of Cleaner Production 10, 237-245 (2002)

21. Guidat, T., Barquet, A.P., Widera, H., Rozenfeld, H., Seliger, G.: Guidelines for the Definition of Innovative Industrial Product-service Systems (PSS) Business Models for Remanufacturing. Procedia CIRP 16, 193-198 (2014)

22. Velamuri, V.K., Bansemir, B., Neyer, A.-K., Möslein, K.M.: Product Service Systems as a Driver for Business Model Innovation: Lessons Learned from the Manufacturing Industry. International Journal of Innovation Management 17, 1-25 (2013)

23. Vargo, S.L., Lusch, R.F.: Institutions and Axioms: An Extension and Update of Servicedominant Logic. J. of the Acad. Mark. Sci. 44, 5-23 (2016)

24. Costa, N., Patrício, L., Morelli, N., Magee, C.L.: Bringing Service Design to Manufacturing Companies: Integrating PSS and Service Design approaches. Design Studies 55, 112-145 (2018)

25. Tukker, A.: Eight Types of Product-service System: Eight Ways to Sustainability? Experiences from SusProNet. Bus. Strat. Env. 13, 246-260 (2004)

26. Raddats, C., Kowalkowski, C., Benedettini, O., Burton, J., Gebauer, H.: Servitization: A Contemporary Thematic Review of Four Major Research Streams. Industrial Marketing Management 83, 207-223 (2019)

27. Bocken, N.M.P., Short, S.W., Rana, P., Evans, S.: A Literature and Practice Review to Develop Sustainable Business Model Archetypes. Journal of Cleaner Production 65, 42-56 (2014)

28. Yang, M., Evans, S.: Product-service System Business Model Archetypes and Sustainability. Journal of Cleaner Production 220, 1156-1166 (2019)

29. vom Brocke, J., Debortoli, S., Müller, O., Reuter, N.: How In-memory Technology Can Create Business Value: Insights from the Hilti Case. CAIS 34 (2014)

30. Barney, J.B.: Resource-based Theories of Competitive Advantage: A Ten-year Retrospective on the Resource-based View. Journal of Management 27, 643-650 (2001)

31. Wade, M., Hulland, J.: Review: The Resource-based View and Information Systems Research: Review, Extension, and Suggestions for Future Research. MIS Quarterly 28, 107142 (2004)

32. Day, G.S.: The Capabilities of Market-driven Organizations. Journal of Marketing 58, 3752 (1994)

33. de Bruin, Tonia, Rosemann, M., Freeze, R., Kaulkarni, U.: Understanding the Main Phases of Developing a Maturity Assessment Model. In: Proceedings of Australasian Conference on Information Systems (ACIS), pp. 8-19 (2005)

34. Mettler, T.: Maturity Assessment Models: A Design Science Research Approach. International Journal of Society Systems Science (IJSSS) 3, 81-98 (2011) 
35. Pöppelbuss, J., Niehaves, B., Simons, A., Becker, J.: Maturity Models in Information Systems Research: Literature Search and Analysis. Communications of the Association for Information Systems 29, 505-532 (2011)

36. Lasrado, L.A., Vatrapu, R., Andersen, K.N.: Maturity Models Development in IS Research: A Literature Review. IRIS: Selected Papers of the Information Systems Research Seminar in Scandinavia 6, 1-64 (2015)

37. Cleven, A.K., Winter, R., Wortmann, F., Mettler, T.: Process Management in Hospitals: an Empirically Grounded Maturity Model. Business Research 7, 191-216 (2014)

38. van Steenbergen, M., van den Berg, M., Brinkkemper, S.: A Balanced Approach to Developing the Enterprise Architecture Practice. In: International Conference on Enterprise Information Systems, pp. 240-253 (2007)

39. Karni, R., Kaner, M.: A Review of Maturity Models and their Application to PSS: Towards a PSS Maturity Model. In: The Philosopher's Stone for Sustainability, pp. 393-398. Springer (2013)

40. Neff, A.A., Hamel, F., Herz, T.P., Uebernickel, F., Brenner, W.: Fostering Efficiency in Information Systems Support for Product-Service Systems in the Manufacturing Industry. In: Proceedings of the 19th Americas Conference on Information Systems, pp. 1-9. Chicago, Illinois (2013)

41. Richter, H.M., Tschandl, M.: Service Engineering-Neue Services erfolgreich gestalten und umsetzen. In: Dienstleistungen 4.0, pp. 157-184. Springer (2017)

42. Hevner, A.R., March, S.T., Park, J., Ram, S.: Design Science in Information Systems Research. MIS Quarterly 28, 75-105 (2004)

43. van Steenbergen, M., Bos, R., Brinkkemper, S., van de Weerd, I., Bekkers, W.: The Design of Focus Area Maturity Models. In: International Conference on Design Science Research in Information Systems, pp. 317-332 (2010)

44. vom Brocke, J., Simons, A., Niehaves, B., Niehaves, B., Reimer, K., Plattfaut, R., Cleven, A.: Reconstructing the Giant: On the Importance of Rigour in Documenting the Literature Search process. ECIS Proceedings 161 (2009)

45. Simon, D., Fischbach, K., Schoder, D.: Enterprise Architecture Management and its Role in Corporate Strategic Management. Inf Syst E-Bus Manage 12, 5-42 (2014)

46. Rosemann, M., vom Brocke, J.: The Six Core Elements of Business Process Management. In: Handbook on Business Process Management 1, pp. 105-122. Springer (2015)

47. Gimpel, H., Hosseini, S., Huber, R., Probst, L., Röglinger, M., Faisst, U.: Structuring Digital Transformation: A Framework of Action Fields and its Application at ZEISS. Journal of Information Technology Theory and Application 19, 31-54 (2018)

48. El Sawy, O.A., Kræmmergaard, P., Amsinck, H., Vinther, A.L.: How LEGO Built the Foundations and Enterprise Capabilities for Digital Leadership. MIS Quarterly Executive 15 (2016)

49. Wewior, J.W.: Role-play Based Assessment of IPS2-specific Intellectual Capital. Procedia CIRP 30, 415-420 (2015)

50. Kiel, D., Arnold, C., Voigt, K.-I.: The Influence of the Industrial Internet of Things on Business Models of Established Manufacturing Companies-A Business Level Perspective. Technovation 68, 4-19 (2017) 
51. Fleisch, E., Weinberger, M., Wortmann, F.: Business Models and the Internet of Things. In: Interoperability and Open-Source Solutions for the Internet of Things, pp. 6-10. Springer (2015)

52. Oliva, R., Kallenberg, R.: Managing the Transition from Products to Services. International Journal of Service Industry Management 14, 160-172 (2003)

53. Kim, Y.S., Lee, S.W., Kim, S.R., Jeong, H., Kim, J.H.: A Product-Service Systems Design Method with Integration of Product Elements and Service Elements Using Affordances. In: ServDes. 2012 Conference Proceedings Co-Creating Services; The 3rd Service Design and Service Innovation Conference; 8-10 February; Espoo; Finland, pp. 111-119 (2013)

54. Morelli, N.: Designing Product/Service Systems: A Methodological Exploration. Design Issues 18, 3-17 (2002)

55. Klötzer, C., Pflaum, A.: Toward the Development of a Maturity Model for Digitalization within the Manufacturing Industry's Supply Chain. Proceedings of the 50th Hawaii International Conference on System Sciences (2017)

56. Müller, J.M., Buliga, O., Voigt, K.-I.: Fortune Favors the Prepared: How SMEs Approach Business Model Innovations in Industry 4.0. Technological Forecasting and Social Change 132, 2-17 (2018)

57. Porter, M.E., Heppelmann, J.E.: How Smart, Connected Products are Transforming Competition. Harvard Business Review 92, 64-88 (2014)

58. Berghaus, S., Back, A.: Disentangling the Fuzzy Front End of Digital Transformation: Activities and Approaches. In: Proceedings of the 38th International Conference on Information Systems (ICIS) (2017)

59. Silva, L., Poleto, T., Moura, J., Paula Costa, A.: An Analysis of and Perspective on the Information Security Maturity Model: a case study of a Public and a Private Sector Company. In: Proceedings of the 18th Americas Conference on Information Systems (AMCIS), 11 (2012)

60. Schumacher, A., Nemeth, T., Sihn, W.: Roadmapping towards Industrial Digitalization based on an Industry 4.0 Maturity Model for Manufacturing Enterprises. Procedia CIRP 79, 409-414 (2019)

61. Paschou, T., Adrodegari, F., Rapaccini, M., Saccani, N., Perona, M.: Towards Service 4.0: A New Framework and Research Priorities. Procedia CIRP 73, 148-154 (2018) 